\title{
The educational preparation of nurses in a developing economy and patient mortality
}

Ziyad R Mahfoud ${ }^{1}$, Ioannis Gkantaras ${ }^{2}$, Anne Elizabeth Topping ${ }^{3}$, Ann Marie Cannaby ${ }^{4}$, Brent Foreman $^{5}$, Roger Watson ${ }^{6}$, David R. Thompson ${ }^{7}$ and Richard Gray ${ }^{8}$

1. Associate Professor, Weill Cornell Medical College, Doha, Qatar

2. Independent Consultant, Athens, Greece

3. Professor of Nursing, Birmingham University, Birmingham, UK

4. Professor of Nursing Science, Birmingham City University, Birmingham, UK

5. Assistant Executive Director of Nursing, Hamad Medical Corporation, Doha, Qatar

6. Professor of Nursing, The University of Hull, Hull, UK

7. Professor of Nursing, The Australian Catholic University, Melbourne, Australia

8. Professor of Clinical Nursing Practice, La Trobe University and Healthscope, Melbourne, Australia

\section{Corresponding author}

Richard Gray, Rm 112, Health Sciences 1, La Trobe University, Science Drive, Melbourne, VIC 3086, Australia. E: r.gray@ latrobe.edu.au, T: +61 481248182

Word count (including abstract): 3,073

\section{Acknowledgements}

We would like to thank Paul Halliday and Akram Mostafa Ibraheem, Director of Health Information Management and HR ERP teams respectively for their contribution in providing access to the relevant data sources and their continuous commitment to excellence at Hamad Medical Corporation. Without their assistance, the particular research project would not have been possible.

\section{Competing interests}

This is the author manuscript accepted for publication and has undergone full peer review but has not been through the copyediting, typesetting, pagination and proofreading process, which may lead to differences between this version and the Version of Record. Please cite this article as doi: $10.1111 /$ inr.12450

This article is protected by copyright. All rights reserved 
Nurse education and patient mortality

The authors declare they have no competing interests

\section{Funding}

No funding was received for this project

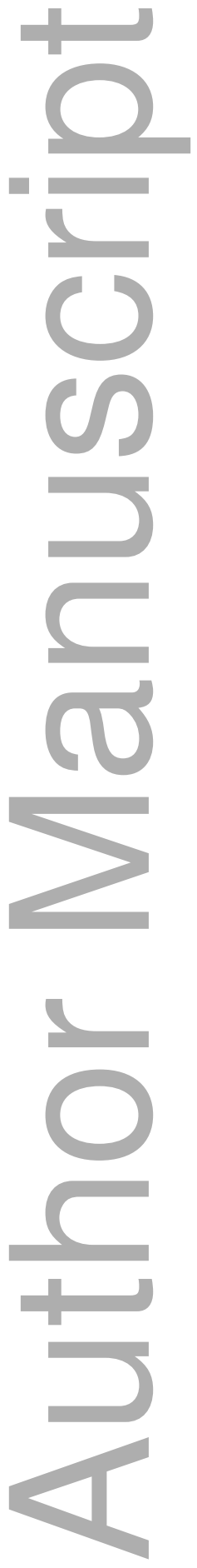




\section{Article type :Original Article \%riginat \\ - (1) \\ The educational preparation of nurses in a developing economy and patient mortality}

\section{Abstract}

Background: Most studies have reported that higher levels (baccalaureate degree) of educational attainment by nurses is associated with lower levels of patient mortality. Researchers working in developed economies (e.g. North America and Europe) have almost exclusively conducted these studies. The value of baccalaureate nurse education has not been tested in countries with a developing economy.

Method: A retrospective observational study conducted in seven hospitals. Patient mortality was the main outcome of interest. Anonymised data were extracted on nurses and patients from two different administrative sources and linked using the staff identification number that exists in both systems. We used bivariate logistic regression models to test the association between mortality and the educational attainment of the admitting nurse (responsible for assessment and care planning).

Results: Data were extracted for 11,918 patients and 7,415 nurses over the first six months of 2015. The majority of nurses were educated in South Asia and just over half were educated to at least bachelor degree level. After adjusting for confounding and clustering, nurse education was not found to be associated with mortality $(\mathrm{OR}=1 \cdot 34,95 \%$ confidence interval $=\cdot 569,3 \cdot 156)$. 
Implications for nursing and health policy: Our observations may suggest that in a developing economy the academic level of nurses' education is not associated with a reduction in patient mortality. Findings should be interpreted with considerable caution but do challenge widely held assumptions about the value of baccalaureate prepared nurses. Further research focused on nursing education in developing economies is required to inform health policy and planning.

Keywords: nurse, education, RN4Cast, observational, mortality, Qatar, developing economy

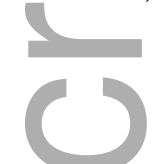

\section{Introduction}

The education of nurses is central to ensuring that health care is provided in a safe and effective manner and that the best possible outcomes are achieved for patients. The authors of the Future of Nursing Report (2010) recommend increasing the percentage of nurses who hold a bachelor degree to $80 \%$ of the American workforce by 2020. It is argued that patients that are cared for by more highly educated nurses will have better clinical outcomes because their thinking is more critical and their practice is more autonomous and evidence based (Yakusheva et al. 2014).

\section{Background}

We conducted a review of the literature on the association between educational attainment of nurses and clinical outcomes for patients. We identified 19 observational studies (Aiken et al. 2014, 2011, 2003, Blegen et al. 2001, 2001; Dilles et al. 2010; Estabrooks et al. 2005; Kelly et al. 2014; Kutney-Lee et al. 2013; Kutney-Lee and Aiken, 2008; Lucero et al. 2010; Ma et al. 2015; McHugh et al. 2013; Sales et al. 2008; Sasichay-Akkadechanunt et al. 2003; Sermeus et al. 2011; Van den Heede et al. 2009; Yakusheva et al. 2014). Most report a positive association (15/19). Half (10/19) focused exclusively on outcomes in surgical patients.

We assessed the methodological quality of these studies using a standardized risk of bias measure (Carlson and Morrison, 2009) for observational research. The majority of studies had a relatively low risk of bias. Potential sources of bias related to the use of self-report questionnaires to determine the educational preparation of nurses and a failure to link of nurses 
included in studies with actual patients they cared for. We also noted that a number of investigators failed to adequately account for the effects of clustering in their analysis (Dilts et al. 1995).

The fieldwork for most studies was conducted in North America and Europe (developed economies) with modern health care systems where nurses - arguably - practice with a high level of autonomy and independence. In the developing economies of Asia, Africa, the Middle East and Eastern Europe, there is considerable variability in models of educational preparation of nurses. There are also marked disparities in the professional standing and autonomy of nursing in the countries where these nurses practice. We argue that research establishing the value of higher levels of nurse education cannot simply be generalized from developed to developing economies. As far as we can determine there have only been two studies that have tested the association between level of nurse education and patient outcomes in a developing economy (Gkantaras et al. 2016; Sasichay-Akkadechanunt et al. 2003). Consequently, there is a need to further test this association in these countries. These observations will help inform health policy and strategic planning at both a hospital and country level.

\section{Objective}

The objective of this study was to test the association between the educational preparation of the admitting nurse (responsible for initial patient assessment and care planning) and patient mortality in the health system of a developing economy (Qatar).

\section{Methods}

Study Design

We carried out a retrospective observational study using anonymised data extracted from routine administrative sources. We were able to link patient and nurse records using the nurses' staff identification number. This approach confers an important advantage over previously used methodologies in that we are directly linking patients with the nurse who was responsible for assessing and planning their care. We extracted the data for the first six months (January through June) of 2015. Nurse data were extracted at the same time but from a separate database. To this 
data set, we added - as potential confounders - hospital level nurse satisfaction data and staffing ratios.

We have adhered to STROBE (Strengthening the Reporting of Observational studies in Epidemiology, von Elm et al. 2007) reporting guidelines when drafting this manuscript.

\section{Setting}

The data were extracted from the administrative records of patients admitted to seven public hospitals in the state of Qatar (3 general and 4 specialist hospitals with a mix of medical, obstetric, oncology, paediatric and surgical wards). We did not include mental health services because of the unique nature of this group of patients. Qatar is a sovereign country located in Western Asia, on the north-eastern coast of the Arabian Peninsula. It has a population of just over 2.7 million people, the vast majority of which are migrant workers involved in construction and the oil and gas industry (Worldometers 2017). The state operates a public health system that provides around $95 \%$ of the countries healthcare needs. The vast majority of the 8695 nurses working in the health system are qualified (i.e. there are almost no nursing assistants or aids) and staff turnover is less than half of a per cent per year. Around $1 \%$ of the nursing workforce are 'Qatari nationals', the majority are migrants.

\section{Participants}

All admitted patients and the nurses responsible for their admission and subsequent care planning. The final dataset comprised 12830 patients and 7415 nurses.

\section{Patients}

We included all male and female patients admitted to participating hospitals. Patients admitted via the emergency department were excluded because of the risk of death without receiving any nursing care. Patients readmitted with the same diagnosis within 30 days were excluded from the analysis. We also excluded patient records with missing data.

Nurses 
All female and male nurses working on participating inpatient wards who had admitted at least one included patient. Nurses with no recorded educational qualification were excluded.

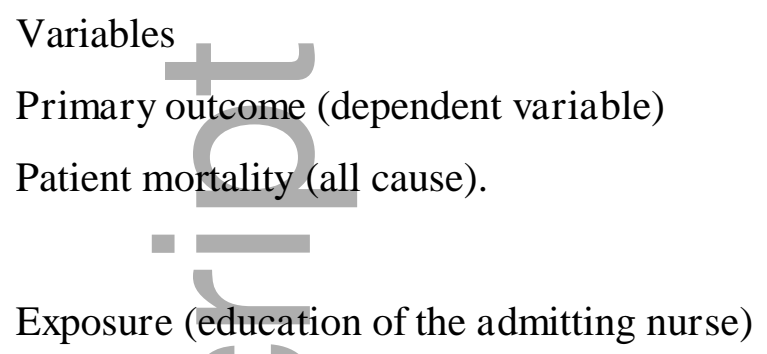

Data about the educational preparation of nurses were extracted from administrative sources. Nurses were initially coded into four groups (licensed, diploma, bachelor or post-graduate degree) based on their highest recorded academic qualification. When nurses are employed, their qualifications go through a rigorous check called credentialing. This process includes contacting the institution that awarded qualifications to check their authenticity. We believe this process that does not rely on the self-report methods used in previous research - gives our educational attainment measure a high degree of validity.

All registered nurses - as part of their scope of practice - working in the health system were responsible for and expected to admit patients and plan their subsequent care. Although more than one nurse provides patient care during an admission, the admitting nurse is responsible for planning the patient care that will subsequently be delivered by the ward nurses. We argue that the effects of higher educational attainment (critical thinking, evidence-based care) would be expressed during the admission and care planning process.

\section{Data Sources}

\section{Patients}

We extracted the following additional patient information from the administrative record: age (on admission to hospital), gender, length of stay (days). Patients' acuity was scored on a zero to three scale, a higher score indicating the patient's condition was judged more serious (i.e. life threatening).

Nurses 
Other variables extracted from the database were gender, age (in years), country of origin, and the hospital and ward where they usually worked.

\section{Contextual information}

The vast majority of the included nurses had also completed the NDNQI (The National Database

of Nursing Quality Indicators) satisfaction survey that is a widely used measure of nurse satisfaction (Taunton et al. 2004). The measure contains 32 items covering five main areas: workload, remuneration, autonomy and decision-making, interaction with colleagues, management and administration and professional development. The satisfaction figure we attached to each nurse is the aggregate result computed for each hospital, as the NDNQI results are anonymous. We have also calculated the staffing ratios for each hospital, for every day of the study by dividing the patients treated each day by the number of nurses with an active clinical role on that day and in that facility. This is a standard approach to calculating staffing ratios (Kutney-Lee and Aiken, 2008).

\section{Data coding and checking}

It was necessary to recode some of the original data to enable meaningful analysis. Nurses' educational attainment was coded into two (1. licensed/diploma and 2. bachelor/postgraduate degree) from our initial four groups. The nationality of nurses was divided into five groups: MENA (Middle East and North Africa), Africa (Sub Saharan), East and South East Asia (Japan, China, Mongolia, South Korea, Noth Korea, Taiwan, Indonesia, Singapore, Malaysia, Philippines, East Timor, Brunei, Laos, Christmas Island, Cambodia, Myanmar (Burma), Thailand and Vietnam), South Asia (India, Pakistan, Bangladesh, Nepal, Bhutan, Sri Lanka) and Western countries (Europe, North America and Australia), based on their geographical coherence and the maturity of their health systems. The same coding was used for patients' nationality. Acuity was recoded into a categorical variable $(\leq 1=$ low, $\geq 2=$ high) for the purposes of our analysis because we expected there would be few patients with the highest ratings.

\section{Ethical considerations}

All members of staff working in the national health system of Qatar are identified by a unique corporation number that enabled us to link nurse and patient data. The identification numbers of 
the patients and nurses were encrypted to avoid any exposure of sensitive data. The date of birth of both patients and nurses was substituted with their age in years, for similar reasons. The study was reviewed by the Medical Research Centre at Hamad Medical Corporation and approved as a quality improvement project (reference number 16107/16).

\section{Statistical Analysis}

We used descriptive statistics to describe patient and nurse demographic, educational and clinical characteristics. Bivariate and multivariate logistic regressions were used to determine the association between the dependent variable (mortality at discharge) and nurse education level after adjusting for confounding. To adjust for the possible correlations between patients cared for by the same nurse, the standard errors of the logistic regression were adjusted for such possible clustering. All analyses were done using STATA version 12 (College Station, Texas, United States of America). We considered as significant a $\mathrm{p}$-value of $\leq \cdot 05$.

\section{Results}

Patients

Over the six-month study period, there were 14,974 admissions to the participating hospitals, of which 946 records were incomplete or inaccurate (e.g. records with negative length of stay). Additionally, there were 1,198 Emergency Department records that were discarded. A total of 12,830 (409 surgical, 4,206 elective, 7,168 obstetric and 1,047 oncology) records met the inclusion criteria and were included in the study.

\footnotetext{
Demographic and clinical characteristics

Most of the patients were females in their mid-thirties. The majority were from the MENA region (table one).
}

Nurses

We identified 7,415 nurses linked with at least one included patient.

Demographic and educational characteristics 
Table two shows the demographic characteristics of participating nurses. The majority were female, from South Asia, in their late 30s. Just over half were educated to at least baccalaureate level.

The majority of nurses in the participating wards completed the NDNQI survey that was administered in January 2015. Responses suggest that nurses were generally satisfied, particularly in the areas of task allocation, interaction, autonomy and professional development.

\section{Outcome data}

Outcome data are also summarised in table one. There were a total of $359(3.01 \%)$ deaths over the six-month study period. Approximately three quarters of those who died had an acuity-rating indicative of them being more severely ill. Patients on average spent three days in hospital. The mean staffing ratio was just over seven patients per nurse.

Main results (table three)

After adjusting for clustering and for nurse and patient age, gender and nationality; patient acuity and length of stay; and nurse satisfaction and staffing ratios, we found no significant association between nurse's education and patient mortality $(\mathrm{OR}=1 \cdot 34,95 \% \mathrm{CI}=\cdot 569,3 \cdot 156, \mathrm{p}=\cdot 501)$.

\section{Discussion}

The primary aim of this study was to test the association between the level of educational attainment of the admitting nurse and patient mortality. In our adjusted model, we found no significant association. Our observation is not consistent with much of the published research from the USA and Europe that clearly shows a relationship between nurses educational attainment and patient mortality (Estabrooks et al. 2005; Kelly et al. 2014). Few studies have tested this association in a developing economy. Authors of a previous study conducted in Thailand also did not show an association between education and mortality (SasichayAkkadechanunt et al. 2003). One possible conclusion from our study is that the education of nurses in developing economies is not an important factor in determining patient mortality. Nurses in this study come from a diverse educational background and perhaps not all bachelor's 
degrees are comparable (i.e. a degree is not always a degree). There are a number of alternative explanations that require consideration.

A task focused model of care delivery

The model of nursing care delivery in Qatar is generally task focused (tasks often being prescribed by medical colleagues). This may mean that the value of higher levels of education are curtailed by the system within which the nurses find themselves working.

Baccalaureate prepared nurses look after sicker patients

We might expect nurses with higher levels of educational attainment to focus their efforts on patients with more complex care needs who ultimately might represent a greater mortality risk. We extracted patients' acuity as a potential confounder and adjusted for this in our analysis. This has not been done in previous studies such as RN4CAST (Aiken et al 2014) - that reported diagnosis - and is a notable strength of our methodological approach.

Misplaced focus on the admitting nurse

The focus of this study was on the patients' admitting nurse who provided only a modest proportion of the bedside care patients receive. However, directly linking nurses with patients they cared for is a particular methodological advantage of our approach.

The effect of migration status

The vast majority of nurses in this study were educated in India and the Philippines and moved to Qatar to work. Often nurses are working overseas to support (extended) families at home. At one level, our observations might reflect differences in the educational systems in different parts of the world. However, it is conceivable that nurses working as 'guests' in a country with a rather dubious human rights record may have found it difficult - or deliberately chose not to challenging the way in which nursing care was delivered on the ward (Avenue et al. 2017).

Limitations

This article is protected by copyright. All rights reserved 
This was a comparative modest study in terms of sample size. Given that the outcome (mortality) is rare $(3.01 \%)$, this comparative study is modest in terms of sample size. A replication of this study with a larger sample size is recommended

\section{Methodological issues}

In this study, we linked patients with the nurse who planned their care in a methodologically novel way. The linkage of the two datasets was performed in a deterministic and unambiguous manner that contrasts with previous studies (Adams et al. 1997; Ford et al. 2006) Our analysis also takes into account clustering; this is an important methodological issue that some similar authors have not adequately addressed (Dilles et al. 2010; Estabrooks et al. 2005).

Previous studies have relied on surveys of nurses to determine their levels of educational preparation. Response rates of a half to two-thirds of nurses have been defended by authors as being good in health services research (Aiken et al. 2014). Whilst this may be true, there remains a distinct possibility of measurement error. In this study, we measured the education of nurses using a methodology that is almost certainly much more precise.

\section{Implications for nursing and health policy}

This is a modest study conducted in a developing economy. Health systems in developed and developing economies are different in a number of important way that include the status and autonomy of nurses. In our view, it is not appropriate to generalise observations from one (developed) to the other (developing). Our study challenges convention that the level of educational attainment of nurses is associated with better patient outcomes (in this case mortality). We are, however, extremely cautious about our findings. There seems to us to be a need to examine in a larger - perhaps multi country - study the association between nurse education and outcomes for patients in developing economies. These observations are important to inform local and national nursing workforce planning.

\section{Author contributions}

Developed the idea for the study; RG, IG, AT, AMC, RW, RW and DT

Principal investigator for the study; RG 
Set up the databases; IG and ZM

Data extraction; IG. ZM, RG

Assessed the quality of the extracted data and did the analyses: IG

Contributed to interpretation of data; RG, BF, AT, AMC, RW and DT

Wrote the first draft of the paper; RG

All authors contributed to the final manuscript.

\section{References}

Adams, M.M. et al. (1997) Constructing Reproductive Histories by Linking Vital Records. American Journal of Epidemiology. 145: 339-348. doi:10.1093/oxfordjournals.aje.a009111

Aiken, L.H. et al. (2011) Effects of nurse staffing and nurse education on patient deaths in hospitals with different nurse work environments. Medical Care. 49: 1047-1053.

doi:10.1097/MLR.0b013e3182330b6e

Aiken, L.H. et al. (2003) Educational Levels of Hospital Nurses and Surgical Patient Mortality. The Journal of the American Medical Association. 290: 1617-1623.

doi:10.1001/jama.290.12.1617

Aiken, L.H., et al. 2014. Nurse staffing and education and hospital mortality in nine European countries: a retrospective observational study. Lancet. 383: 1824-1830. doi:10.1016/S0140$6736(13) 62631-8$

Blegen, M.A., Vaughn, T.E., \& Goode, C.J. (2001) Nurse experience and education: effect on quality of care. Journal of Nursing Administration. 31: 33-39.

Carlson, M.D.A., Morrison, R.S., 2009. Study Design, Precision, and Validity in Observational Studies. Journal Palliative Medicine. 12: 77-82. doi:10.1089/jpm.2008.9690 
Dilles, T. et al. (2010) Nurses' practices in pharmacotherapy and their association with educational level. Journal of Advanced Nursing. 66: 1072-1079.

Dilts, D., Khamalah, J. \& Plotkin, A. (1995) Using cluster analysis for medical resource decision making. Medical Decision Making. 15: 333-347. doi:10.1177/0272989X9501500404

Estabrooks, C.A. et al. (2005) The impact of hospital nursing characteristics on 30-day mortality. Nursing Research 54: 74-84.

Ford, J.B., Roberts, C.L., Taylor, L.K., 2006. Characteristics of unmatched maternal and baby records in linked birth records and hospital discharge data. Paediatr. Perinat. Epidemiol. 20, 329337. doi:10.1111/j.1365-3016.2006.00715.x

Gkantaras, I. et al. (2016) The effect of Nurse GraduaTeness on patient mortality: a crosssectional survey (the NuGaT study). Journal of Advance Nursing. 72: 3034-3044. doi:10.1111/jan.13059

IMF World Economic Outlook (2015) Uneven Growth: Short- and Long-Term http://www.imf.org/external/pubs/ft/weo/2015/01/ (accessed 7.14.17).

Kelly, D.M. et al. (2014) Impact of critical care nursing on 30-day mortality of mechanically ventilated older adults. Critical Care Medicine. 42: 1089-1095.

doi:10.1097/CCM.0000000000000127

Kutney-Lee, A. \& Aiken, L.H. (2008) Effect of Nurse Staffing and Education on the Outcomes of Surgical Patients with Comorbid Serious Mental Illness. Psychiatric Services 59: 1466-1469. doi:10.1176/appi.ps.59.12.1466

Kutney-Lee, A., Sloane, D.M. \& Aiken, L.H. (2013) An Increase in The Number Of Nurses With Baccalaureate Degrees Is Linked To Lower Rates Of Postsurgery Mortality. Health Affairs. 32: 579-586. doi:10.1377/hlthaff.2012.0504 
Lucero, R.J., Lake, E.T. \& Aiken, L.H. 2010. Nursing care quality and adverse events in US hospitals. Journal of Clinical Nursing 19: 2185-2195. doi:10.1111/j.1365-2702.2010.03250.x

Ma, C., McHugh, M.D. \& Aiken, L.H. (2015) Organization of Hospital Nursing and 30-day Readmissions in Medicare Patients Undergoing Surgery. Medical Care. 53: 65-70. doi:10.1097/MLR.0000000000000258

McHugh, M.D. et al. (2013) Lower mortality in magnet hospitals. Medical Care. 51: 382-388. doi:10.1097/MLR.0b013e3182726cc5

Sales, A. et al. (2008) The association between nursing factors and patient mortality in the Veterans Health Administration: the view from the nursing unit level. Medical Care. 46: 938945. doi:10.1097/MLR.0b013e3181791a0a

Sasichay-Akkadechanunt, T., Scalzi, C.C., Jawad, A.F., 2003. The relationship between nurse staffing and patient outcomes. Journal of Nursing Administration. 33: 478-485.

Sermeus, W. et al. (2011) Nurse forecasting in Europe (RN4CAST): Rationale, design and methodology. BMC Nursing 10: 6. doi:10.1186/1472-6955-10-6

Taunton, R.L., Bott, M.J., Koehn, M.L., Miller, P., Rindner, E., Pace, K., et al. 2004. The NDNQI-Adapted Index of work satisfaction. Journal of Nursing Measurement. 12: 101-122.

The Future of Nursing: Leading Change, Advancing Health [WWW Document], 2010 URL http://www.nationalacademies.org/hmd/Reports/2010/The-Future-of-Nursing-Leading-ChangeAdvancing-Health.aspx (accessed 7.14.17).

Van den Heede, K. et al. (2009) The relationship between inpatient cardiac surgery mortality and nurse numbers and educational level: Analysis of administrative data. International Journal of Nursing Studies. 46: 796-803. doi:10.1016/j.ijnurstu.2008.12.018 
von Elm, E. et al. (2007) The Strengthening the Reporting of Observational Studies in Epidemiology (STROBE) statement: guidelines for reporting observational studies. Lancet. 370: 1453-1457. doi:10.1016/S0140-6736(07)61602-X

Yakusheva, O., Lindrooth, R. \& Weiss, M. (2014) Economic evaluation of the $80 \%$ baccalaureate nurse workforce recommendation: a patient-level analysis. Medical Care. 52: 864869. doi:10.1097/MLR.0000000000000189

Worldometers (2017) Qatar Population http://www.worldometers.info/world-population/qatarpopulation/(accessed 7.14.17).

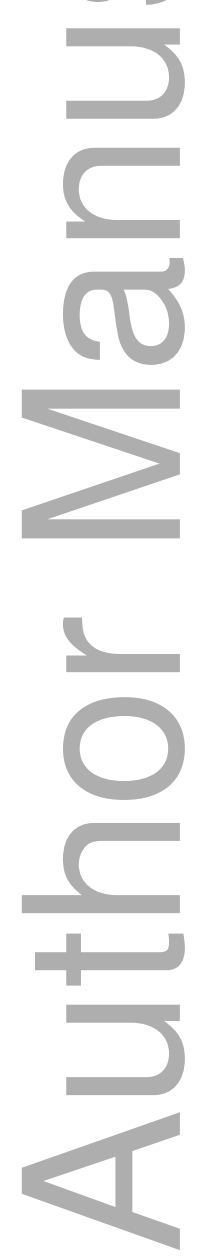




\section{University Library}

\section{- M M N E R VA A gateway to Melbourne's research publications}

Minerva Access is the Institutional Repository of The University of Melbourne

Author/s:

Mahfoud, ZR;Gkantaras, I;Topping, AE;Cannaby, AM;Foreman, B;Watson, R;Thompson, $D R ; G r a y, ~ R$

Title:

The educational preparation of nurses in a developing economy and patient mortality.

Date:

2018-09

Citation:

Mahfoud, Z. R., Gkantaras, I., Topping, A. E., Cannaby, A. M., Foreman, B., Watson, R., Thompson, D. R. \& Gray, R. (2018). The educational preparation of nurses in a developing economy and patient mortality.. Int Nurs Rev, 65 (3), pp.434-440. https://doi.org/10.1111/ inr.12450.

Persistent Link:

http://hdl.handle.net/11343/283671 